\title{
Escherichia coli 0157:H7-Clinical aspects and novel treatment approaches
}

\author{
Elias A. Rahal ${ }^{\dagger}$, Natalie Kazzi, Farah J. Nassar and Ghassan M. Matar *t \\ Faculty of Medicine, Department of Experimental Pathology, Immunology and Microbiology, American University of Beirut, Beirut, Lebanon
}

Edited by:

Nora L. Padola, Universidad Nacional del Centro de la Provincia de

Buenos Aires, Argentina

Reviewed by:

Charles M. Dozois, Institut National de la Recherche Scientifique,

Canada

Ramon A. Exeni, Hospital Niños San Justo, Argentina

*Correspondence:

Ghassan M. Matar, Faculty

of Medicine, Department

of Experimental Pathology,

Immunology and Microbiology,

American University of Beirut, Riad

El-Solh, PO Box 11-0236, Beirut 1107

2020, Lebanon.

e-mail:gmatar@aub.edu.lb

${ }^{\dagger}$ These authors equally contributed

to this work.
Escherichia coli $0157: \mathrm{H7}$ is a notorious pathogen often contracted by intake of contaminated water or food. Infection with this agent is associated with a broad spectrum of illness ranging from mild diarrhea and hemorrhagic colitis to the potentially fatal hemolytic uremic syndrome (HUS). Treating E. coli O157:H7 infection with antimicrobial agents is associated with an increased risk of severe sequelae such as HUS. The difficulty in treating this bacterium using conventional modalities of antimicrobial agent administration has sparked an interest in investigating new therapeutic approaches to this bacterium. These approaches have included the use of probiotic agents and natural products with variable success rates. In addition, novel modalities and regimen of antimicrobial agent administration have been assessed in an attempt at decreasing their association with aggravating infection outcomes.

Keywords: Escherichia coli 0157:H7, hemolytic uremic syndrome, hemorrhagic colitis, shiga toxins, antimicrobial chemotherapy

\section{GENERAL CHARACTERISTICS OF E. coli 0157:H7}

The identification of E. coli O157:H7 as the etiologic agent of an outbreak of gastroenteritis that occurred in 1982 (Riley et al., 1983) has led to the recognition of a novel class of E. coli, the Enterohemorrhagic E. coli (EHEC). This group of pathogenic E. coli includes those that cause a clinical disease similar to that caused by E. coli O157:H7 and that possess few other characteristics of this organism, namely producing one or more phage-encoded Shiga toxins, possessing a hemolysinencoding $60 \mathrm{MDa}$ plasmid and that cause attaching and effacing (A/E)lesions (Levine, 1987; Nataro and Kaper, 1998).E. coli O157:H7 produces either or both of two toxins, one neutralized by antisera to shiga toxin produced by Shigella dysenteriae type 1 and referred to as Shiga toxin 1 (Stx1) while the other, Shiga toxin 2 (Stx2), is not neutralized by these antisera (Strockbine et al., 1986). Although E. coli O157:H7, like other E. coli ferments lactose, it does not ferment sorbitol within $48 \mathrm{~h}$, unlike $80-95 \%$ of E. coli isolated from human stools (March and Ratnam, 1986). On the other hand, it does not grow well at $44-45.5^{\circ} \mathrm{C}$, which is the default incubation temperature for detection of E. coli in food and water sources (Raghubeer and Matches, 1990).

Disease caused by E. coli O157:H7 has been reported from more than 30 countries on six continents (Doyle et al., 2001). In a 20 -year surveillance period in the USA, 350 outbreaks were reported (Rangel et al., 2005). The Center for Disease Control and Prevention (CDC) estimates that E. coli O157: H7 causes 73,480 illnesses, 2168 hospitalizations and 61 deaths per year in the USA alone (Mead et al., 1999). E. coli O157:H7 has been found in cattle of several countries including the USA, Canada, Germany, Spain, England, and Scotland (Armstrong et al., 1996). Outbreaks have also occurred in these countries, as well as in Japan (Michino et al., 1999).

Cattle are considered to be the chief animal reservoir for $E$. coli O157:H7, which is a temporary member of their normal gut micro flora (Caprioli et al., 2005). E. coli O157:H7 has been isolated from many healthy cattle and has not been shown to be a pathogen in these animals. Cattle seem to lack vascular receptors for shiga-like toxins (Pruimboom-Brees et al., 2000). E. coli O157:H7 has also been isolated from other animals including deer (Diaz et al., 2011), sheep (Urdahl et al., 2003), horses (Lengacher et al., 2010), goats (Mersha et al., 2010), and dogs (Kataoka et al., 2010).

The first outbreak of E. coli O157:H7 occurred in 1982 and was traced to contaminated hamburger meat (Riley et al., 1983). Most outbreaks, particularly those that occurred during the 1980s were food borne with the main culprits being beef products particularly undercooked hamburgers in addition to unpasteurized milk (Griffin and Tauxe, 1991). During the past decade, however, marked changes in the epidemiology of human infections have taken place and outbreaks traced to vegetable and fruit sources, in addition to other food sources are on the rise. Infections traced to white radish sprouts (Michino et al., 1999), fresh spinach (Brandl, 2008), and lettuce (Hilborn et al., 1999). Consumption of tomatoes and apple juice has been frequently involved in outbreaks as well (McDowell and Sheridan, 2001). In addition, waterborne outbreaks have occurred (Swerdlow et al., 
1992; Olsen et al., 2002; Bopp et al., 2003). E. coli O157:H7 appears to be capable of survival for prolonged times in water particularly at lower temperatures (Wang and Doyle, 1998). This microorganism was demonstrated to survive for more than eight months in a farm water gutter, and the surviving organisms were able to colonize cattle (Kudva et al., 1998). Swimming in contaminated water has also resulted in outbreaks (Keene et al., 1994; Friedman et al., 1999; Paunio et al., 1999). Person-toperson transmission has also been reported in day care centers and nursing homes as well (Panaro et al., 1990; Reida et al., 1994).

The rather easy spreading of E. coli O157:H7 from one person to another indicates that the infectious dose is rather low. Moreover, transmission by water, which would tend to dilute the organisms, substantiates this suggestion. The estimated infectious dose from outbreak data is 10-100 CFU (Griffin et al., 1994).

\section{VIRULENCE FACTORS OF E. coli 0157:H7}

The ability to produce one or more shiga toxins is a hallmark E. coli O157:H7 infection. However, toxin production is not sufficient to cause disease. Two other factors are indicted in contributing to the virulence of E. coli O157:H7. The first of these two factors is harboring a $60 \mathrm{MDa}$ virulence plasmid (pO157), which encodes a hemolysin (Schmidt et al., 1996; Mead and Griffin, 1998). The other factor is the locus of enterocyte effacement (LEE) (Kresse et al., 1998; Ogierman et al., 2000).

\section{THE LOCUS OF ENTEROCYTE EFFACEMENT (LEE)}

The LEE contains all the genes necessary for inducing the A/E lesions typical of E. coli O157: H7 infection (Louie et al., 1993; Vallance and Finlay, 2000). As E. coli O157:H7 attaches to the gut mucosa and interacts with it, histopathological changes are produced in the epithelium. These changes are collectively known as A/E lesions (Kresse et al., 2000). These lesions are characterized by effacement of the epithelial brush border microvilli and the formation of actin-rich pedestals within the host cell underneath the attached bacterial cells. The presumed functions of these pedestals are prevention of dislodgement of the bacterium during the host diarrheal response and inhibition of bacterial phagocytosis (DeVinney et al., 1999).

\section{P0157}

All isolates of E. coli O157:H7 harbor the 60 MDa pO157 plasmid. This plasmid contains the hly operon encoding an enterohemolysin (Schmidt et al., 1996). This hemolysin, with the aid of specialized transport systems, may allow the bacterium to utilize the blood released into the intestine as a source of iron (Mead and Griffin, 1998).

\section{SHIGA TOXINS}

The Shiga toxin family comprises three members. Shiga toxin, produced by Shigella dysenteriae type 1, is the prototype Shiga toxin. On the other hand, Stx1 and Stx 2 are produced by the EHEC. Several variants of Stx2 have been identified as well and these include Stx2c, Stx2d, Stx2e, Stx2f, and Stx2g. These share $84-99 \%$ of the amino-acid sequence of Stx2 but differ in some of its biological characteristics (Ito et al., 1990; Melton-Celsa and
O’Brien, 1998; Schmidt et al., 2000; Melton-Celsa et al., 2002; Zheng et al., 2008). Three functional properties characterize the Shiga toxin family. These toxins are cytotoxic to HeLa and Vero cells. They lead to fluid accumulation in ligated rabbit illeal loops; therefore, they are "enterotoxic" and they are capable of inducing paralysis of the hind-legs and death in rabbit and mouse models (Jackson, 1990).

The binding moiety of these toxins, which aids them in binding to human and animal cells, consists of five B subunits. These subunits are non-covalently associated with an $\mathrm{A}$ subunit, which in turn consists of an $A_{1}$ and an $A_{2}$ subunit (Sandvig and Van Deurs, 1996). Shiga toxin and Stxl differ only by a single amino acid in the B subunit (Calderwood et al., 1987; Hofmann, 1993). Thus, they are essentially identical; moreover, Stx1 is neutralized by antiserum to Shiga toxin (O'Brien and Holmes, 1987; Qadri and Kayali, 1998). Stx2 is antigenically distinct and unrelated. It is approximately $55 \%$ homologous to Shiga toxin/Stx1 (Jackson, 1990) and is not neutralized by antiserum to Shiga toxin (Qadri and Kayali, 1998).

The cellular receptors for the Shiga toxins are the neutral glycolipids globotriosylceramide (Gb3) and globotetraosylceramide (Gb4) (Betz et al., 2011). Various cell types are sensitive to Shiga toxins. These include enterocytes, renal, aortic, and brain endothelial cells, mesangial cells, renal tubular and lung epithelial cells, cells of the monocytic lineage, polymorphonuclear cells, in addition to platelets and erythrocytes among other cell types (Meyers and Kaplan, 2000).

After the toxin binds its receptor on the cell membrane, a short incubation leads to aggregation of toxin-receptor complexes in clathrin-coated pits. Next, the A fragment is endocytosed. The toxin is transported through endosomes to the Trans Golgi network (TGN). In the TGN, the toxin is cleaved by the enzyme furin into the $A_{1}$ and $A_{2}$ subunits. From the TGN, the toxin is transported to the endoplasmic reticulum where translocation into the cytosol takes place. If toxin was not cleaved by furin, then the cytosolic enzyme caplain may cleave the molecule (Hofmann, 1993; Sandvig and Van Deurs, 1996). The $A_{1}$ subunit is a $28 \mathrm{~S}$ rRNA N-glycosidase (Jackson, 1990). The toxin cleaves an adenine residue from a specific nucleotide of the $28 \mathrm{~S}$ rRNA component of the $60 \mathrm{~S}$ ribosomal subunit. This blocks tRNA binding to the $60 \mathrm{~S}$ ribosomal subunit thus preventing peptide elongation and disrupting protein synthesis. This leads to cell death (Hofmann, 1993).

Shiga toxins induce an increase in chemokine synthesis from intestinal epithelial cells. This augments host mucosal inflammatory responses with release of interleukins, such as IL-8 and IL-1, in addition to Tumor Necrosis Factor (TNF). Activation of human endothelium by TNF or IL-1 leads to an increase in toxin receptor synthesis and hence increased sensitivity of the cell leading to increased cell death after exposure to the toxins (Meyers and Kaplan, 2000).

E. coli O157:H7 strains may produce either Stx1, Stx2, or both; however, most strains produce Stx2 (Mead and Griffin, 1998). Stx 1 remains mostly cell-associated and stored in the periplasmic space while Stx2 is released from bacterial cells. Therefore, Stx1 is typically predominantly detected in cell lysates, while Stx2 is 
found in higher titers in culture supernatants (Strockbine et al., 1986; Yoh et al., 1997; Sato et al., 2003; Shimizu et al., 2009).

\section{OTHER VIRULENCE FACTORS}

While the LEE, pO157 and Shiga toxin production are defining virulence factors of $E$. coli O157:H7, other factors contribute to its pathogenicity. Some strains harbors EspP, which belongs to the family of serine protease autotransporters of Enterobacteriaceae (SPATE). This protease cleaves pepsin A and human coagulation factor $\mathrm{V}$, which probably contributes to increased hemorrhage into the intestinal tract (Brunder et al., 1997). Moreover, EspP cleaves multiple complement system components hence protecting the bacterium from immune system-mediated elimination (Orth et al., 2010). On the other hand, in addition to LEE members such as intimin and Tir, bacterial attachment to host intestinal cells is also mediated by a type IV pilus referred to as the hemorrhagic coli pilus (HCP) (Xicohtencatl-Cortes et al., 2007). Multiple fimbriae and fimbrial gene clusters have also been implicated in contributing to adherence of this organism to host cells (Low et al., 2006).

\section{CLINICAL ILLNESSES ASSOCIATED WITH E. coli 0157:H7 INFECTIONS}

Infection with E. coli O157:H7 can be asymptomatic or may manifest as non-bloody diarrhea, hemorrhagic colitis, the hemolytic uremic syndrome (HUS), thrombocytopenia purpura and death (Griffin et al., 1988).

\section{HEMORRHAGIC COLITIS}

Unless infection with E. coli O157:H7 is asymptomatic, following an incubation period of 3-4 days (Nauschuetz, 1998), the illness starts with severe abdominal cramps accompanied by a nonbloody diarrhea. In most patients the watery diarrhea becomes grossly bloody after two or three days (Boyce et al., 1995). Fever may be totally absent or may be of the low-grade type and its presence is more common in patients with severe illness (Griffin et al., 1988; Slutsker et al., 1997).

The duration of E. coli O157:H7 shedding seems to be agedependent. Children under five years of age carry the organism after the resolution of symptoms longer than older children and adults (Pai et al., 1988). Intermittent shedding has also been reported (Belongia et al., 1993).

\section{THE HEMOLYTIC UREMIC SYNDROME}

Gastrointestinal symptoms due to infection with E. coli O157:H7 usually resolve within a week. Patients then mostly recover with no major sequelae. Nevertheless, $5-10 \%$ of patients under the age of 10 years develop the HUS approximately one week after onset of hemorrhagic colitis. The release of Shiga toxins is believed to play a central role in the development of HUS (Karmali et al., 1983). HUS most commonly occurs in children between 1 and 5 years of age but it can also occur in other groups particularly hospitalized patients over the age of 60 years. HUS displays a classical triad of microangiopathic hemolytic anemia (with fragmented RBCs on blood film), thrombocytopenia and renal failure (Gasser et al., 1955; Gianantonio et al., 1964). The patient's hematocrit may decline by $10 \%$. Oligouria and hypertension (with elevated serum potassium, blood urea nitrogen, and uric acid levels) may occur as well. A condition known as thrombotic thrombocytopenia purpura (TTP) strikes mostly the adult population and is rarer than HUS. In TTP less marked renal damage is noted and fewer cases have a diarrheal prodrome. Both HUS and TTP can present with neurological abnormalities including seizures, coma and hemiparesis. These two conditions need not always be differentiated and may be referred to as HUS/TTP (Nauschuetz, 1998).

HUS and TTP are non-consumptive coagulopathies i.e., characterized by the consumption of platelets but not of clotting factors. They are regarded as variants of a single syndrome (Van Gorp et al., 1999). While fever and central nervous system (CNS) involvement are more frequent in TTP, renal dysfunction is less, and mortality and recurrences are greater. Although TTP can be initiated by E. coli $\mathrm{O} 157: \mathrm{H} 7$ infection, a diarrheal prodrome is uncommon (Siegler, 1995).

Classical postdiarrheal HUS always involves the colon and the kidney; however, other organ systems may be affected. The brain is most commonly affected with an evidence of CNS dysfunction in nearly one-third of HUS cases. Generalized seizures are common and occur in $<20 \%$ of children affected. CNS injury symptoms range from disorders of posture, movement, and muscle tone to coma. Transient hepatocellular damage occurs in $40 \%$ of cases. The pancreas may be involved leading to diabetes mellitus, pancreatitis, and rarely, exocrine dysfunction. Other organs such as the heart, the lung and the skin are involved in rare cases (Siegler, 1995).

After the onset of the acute phase of HUS, characterized by the already mentioned triad of hemolytic anemia, thrombocytopenia, and acute renal injury, the patient's clinical disease may follow one of several patterns. More than $95 \%$ of cases recover from the acute phase of the disease. Thus, the mortality rate is 5\% (McLigeyo, 1999). Grave sequelae, such as end-stage renal disease or permanent neurologic damage, occur in about $5 \%$ of subjects who survive the acute phase of HUS (Boyce et al., 1995).

Although an E. coli O157:H7 infection may result in HUS and TTP, numerous other causes may result in these diseases.

\section{PATHOGENESIS OF E. coli 0157:H7 INFECTIONS}

The infectious process of E. coli O157:H7 (Figure 1) is initiated by the ingestion a relatively small inoculum of $10-100$ CFUs. Only a few organisms are needed to allow enteric colonization (Mead and Griffin, 1998). The process by which these bacteria become attached to the mucosa of the distal ileum and the colon is complex and likely starts by bacterial fimbrial attachment followed by translocation of the bacterial Tir protein to the host cell membrane. Tir serves as the receptor for intimin, which is a bacterial outer membrane protein that plays a major role in attachment and production of A/E lesions characterized by effacement of microvilli (DeVinney et al., 1999).

Owing to this bacterium's tremendous ability to produce the potent cytotoxic Shiga toxins, invasion of the host cells is not necessary for the progression to hemorrhagic colitis. Although the toxins are probably also not necessary for triggering the diarrhea, they most likely cause the intestinal lesions, characterized by 


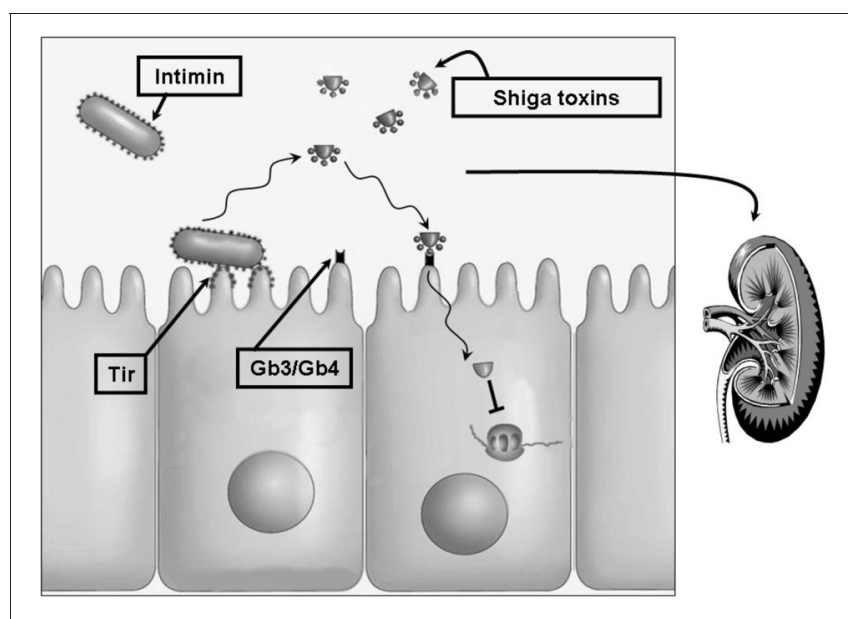

FIGURE 1 | The pathobiologic process of $E$. coli 0157:H7. The complex process by which E. coli O157:H7 attaches to the intestinal mucosa starts by bacterial fimbrial attachment followed by translocation of the bacterial Tir protein into the host cell membrane. Tir serves as the receptor for the bacterial outer membrane attachment protein intimin. One or more types of Shiga toxins are released which then bind to their cellular receptors, the neutral glycolipids Gb3 and Gb4. Internalization and cellular activation of these toxins blocks ribosomal peptide elongation hence disrupting protein synthesis leading to cell death. Intestinal damage permits Shiga toxins and other bacterial factors to gain entrance to the circulation. These may reach multiple host tissues including the kidneys where damage to the microvasculature results in the potentially lethal hemolytic uremic syndrome. Treatment of this disease remains largely supportive with no widely accepted antibacterial or toxin-targeted regimen. Antibacterial agents are believed to result in bacterial lysis and release of stored toxins. One potential treatment method may rely on inhibition of toxin expression prior to administration of a bactericidal agent.

hemorrhage and ulcerations, via damaging the microvasculature of the intestinal wall (Tesh and O'Brien, 1992).

Once the gut-blood barrier has been compromised by intestinal damage, Shiga toxins, and other bacterial products like lipopolysaccharide (LPS) gain entrance to the circulation. LPS can by itself, independent of Shiga toxins, damage endothelial cells, increase TNF levels, activate platelets and induce the blood coagulation cascade. It can also increase levels of interleukins such as IL-8, which is a potent activator of white blood cells (WBCs). WBCs participate in the pathogenic process by elaborating tissue-damaging enzymes such as elastase. Shiga toxins induce an increase in chemokine synthesis from intestinal epithelial cells probably augmenting host mucosal inflammatory responses with release of IL-8, TNF, and IL-1. As mentioned above, activation of human endothelium by TNF or IL-1 leads to an increase in expression of the Shiga toxin cellular receptors. This leads to an increased cell death after exposure to the toxins. Since the toxin receptors are widely distributed on various types of cells, thus many host tissues are affected (Meyers and Kaplan, 2000).

\section{CURRENT AND NOVEL TREATMENT APPROACHES}

Treatment of infection with EHEC strains, including E. coli O157:H7, is mainly based on supportive therapy, particularly rehydration. The use of antimotility agents, which inhibit peristalsis and delay clearance of the organism, poses a risk factor for progression to HUS (Cimolai et al., 1994; Bell et al., 1997). The use of antimicrobial agents in the treatment of E. coli O157:H7 infection is not recommended but remains a debatable issue (Safdar et al., 2002). This is based on studies that have shown it to be a risk factor for the development of HUS (Wong et al., 2000; Smith et al., 2012). Additionally, the use of trimethoprim, the quinolones, or furazolidone enhances the production of Shiga toxins from E. coli O157:H7 in vitro presumably due to lysis of bacterial cells and the release of stored toxins (Kimmitt et al., 2000). This enhanced release of toxins may alternatively be due to induction of Stx-producing prophages harbored by the bacterium. These prophages would be activated by the SOS response, a damage response triggered in these bacteria mostly due to genomic insult which may be exerted by antimicrobial treatment (Kimmitt et al., 2000).

In light of the difficulties in treating this agent, alternate treatment approaches were investigated by multiple groups. Antibodies to Stx2 were shown to enhance the survival of infected gnotobiotic piglets (Donohue-Rolfe et al., 1999). These antibodies were also demonstrated to be well tolerated in humans and thus may be useful for preventing HUS in pediatric subjects (Lopez et al., 2010). On the other hand, carbosilane dendrimers were shown to specifically bind to Shiga toxins with high affinity and to inhibit cellular entry of the toxin. Intravenous administration of these carbosilane dendrimers decreased the brain damage and prevented the lethal effect of the toxins in infected mice (Nishikawa et al., 2002).

The use of natural products for the treatment and prevention of E. coli O157:H7 has been assessed by multiple groups. Studies in infant rabbits show that the administration of Lactobacillus casei, commonly known for its probiotic efficiency, had a protective effect against the toxins of E. coli O157:H7 (Ogawa et al., 2001). Multiple other probiotic agents have been shown to be effective in curbing the growth or the pathogenic effect of this organism (Shu and Gill, 2001, 2002; Asahara et al., 2004; Takahashi et al., 2004; Gagnon et al., 2006; Kim et al., 2009; Etienne-Mesmin et al., 2011; Tahamtan et al., 2011). Certain herbs such as Chinese cinnamon, Spanish oregano and other essential oils have been shown to have mechanisms of action against the cell membrane and cell wall of E. coli O157:H7 (Oussalah et al., 2006). Green tea components (Lee et al., 2009) in addition to cranberry constituents (Lacombe et al., 2010) have also been shown to have an effect against this bacterium. In an attempt at implementing antimicrobial agents in the treatment of an E. coli O157:H7-infected animal model, azithromycin was shown to enhance the survival of infected piglets (Zhang et al., 2009). The majority of the studies mentioned herein have limited their testing to in vitro assays or employed animals that were gnotobiotic or treated with antimicrobial agents to limit the growth of their normal flora prior to infection with E. coli O157:H7. Consequently, the response to the tested agents in a host with a normal range of flora may be different.

Our group examined whether employing an agent that would inhibit toxin expression prior to treatment with a bactericidal antibiotic may be effective in treating such an infection. We assessed the effects of rifampicin, an RNA polymerase inhibitor, and gentamicin, a ribosome inhibitor, on the expression of the 
Stx1 and Stx2 encoding genes, stx1 and stx2 (Kanbar et al., 2003; Matar and Rahal, 2003; Rahal et al., 2011a,b). After incubation with antimicrobial agents, levels of $s t x 1$ gene transcripts notably decreased by more than $99 \%$ in a sample treated with the minimum inhibitory concentration (MIC) of rifampicin, in that treated with the MIC of rifampicin followed by the minimum bactericidal concentration (MBC) of rifampicin and in the sample treated with the MIC of rifampicin followed by the MBC of gentamicin. The sample treated with the MBC of gentamicin alone showed a $51.37 \%$ decrease, which was the least noted toxin gene expression inhibition. A 77\% decrease in stx 2 transcript detection was seen in the sample treated with the MBC of gentamcin alone. Samples treated with the MIC of rifmapicin, or with the MIC of rifampicin followed by the MBC of rifampicin, or with the MIC of rifampicin followed by the MBC of gentamicin showed complete inhibition of stx2 transcript detection. Detection of toxin release from these bacteria using reverse passive latex agglutination (RPLA) yielded results that were mostly concurrent with the decrease in RNA synthesis except for samples treated with the $\mathrm{MBC}$ of gentamicin alone. Gentamicin seemed to trigger an enhanced release of toxins from treated cultures.

To assess the utility of an antimicrobial regimen for the treatment of an animal model of infection, multiple groups of

\section{REFERENCES}

Armstrong, G. L., Hollingsworth, J., and Morris, J. G. Jr. (1996). Emerging foodborne pathogens: Escherichia coli $\mathrm{O} 157: \mathrm{H} 7$ as a model of entry of a new pathogen into the food supply of the developed world. Epidemiol. Rev. 18, 29-51.

Asahara, T., Shimizu, K., Nomoto, K., Hamabata, T., Ozawa, A., and Takeda, Y. (2004). Probiotic bifidobacteria protect mice from lethal infection with Shiga toxinproducing Escherichia coli O157:H7. Infect. Immun. 72, 2240-2247.

Bell, B. P., Griffin, P. M., Lozano, P., Christie, D. L., Kobayashi, J. M., and Tarr, P. I. (1997). Predictors of hemolytic uremic syndrome in children during a large outbreak of Escherichia coli O157:H7 infections. Pediatrics 100, E12.

Belongia, E. A., Osterholm, M. T., Soler, J. T., Ammend, D. A., Braun, J. E., and Macdonald, K. L. (1993). Transmission of Escherichia coli O157:H7 infection in Minnesota child day-care facilities. JAMA 269, 883-888.

Betz, J., Bielaszewska, M., Thies, A., Humpf, H. U., Dreisewerd, K., Karch, H., et al. (2011). Shiga toxin glycosphingolipid receptors in microvascular and macrovascular endothelial cells: differential association with membrane lipid raft microdomains. J. Lipid Res. 52, 618-634.
Bopp, D. J., Sauders, B. D., Waring, A. L., Ackelsberg, J., Dumas, N., Braun-Howland, E., et al. (2003). Detection, isolation, and molecular subtyping of Escherichia coli O157:H7 and Campylobacter jejuni associated with a large waterborne outbreak. J. Clin. Microbiol. 41, 174-180.

Boyce, T. G., Swerdlow, D. L., and Griffin, P. M. (1995). Escherichia coli O157:H7 and the hemolytic-uremic syndrome. N. Engl. J. Med. 333, 364-368.

Brandl, M. T. (2008). Plant lesions promote the rapid multiplication of Escherichia coli O157:H7 on postharvest lettuce. Appl. Environ. Microbiol. 74, 5285-5289.

Brunder, W., Schmidt, H., and Karch, H. (1997). EspP, a novel extracellular serine protease of enterohaemorrhagic Escherichia coli O157:H7 cleaves human coagulation factor V. Mol. Microbiol. 24, 767-778.

Calderwood, S. B., Auclair, F., Donohue-Rolfe, A., Keusch, G. T., and Mekalanos, J. J. (1987). Nucleotide sequence of the Shigalike toxin genes of Escherichia coli. Proc. Natl. Acad. Sci. U.S.A. 84, 4364-4368.

Caprioli, A., Morabito, S., Brugere, H., and Oswald, E. (2005). Enterohaemorrhagic Escherichia coli: emerging issues on virulence and modes of transmission. Vet. Res. 36, 289-311.

$\mathrm{BALB} / \mathrm{c}$ mice received $3 \times \mathrm{LD} 50$ of an E. coli O157:H7 strain via intraperitoneal injection. These were then treated with various rifampicin/gentamicin regimen and were monitored for survival. None of the mice infected and left untreated and none of the mice infected but treated with the in vivo MBC equivalent dose of gentamicin survived. On the other hand, the highest survival rate was obtained with the group treated with the in vivo MIC equivalent dose of rifampicin followed by the in vivo $\mathrm{MBC}$ equivalent dose of gentamicin (50\% survival rate). In comparison, $25 \%$ of the mice infected and treated with the in vivo MIC equivalent dose of rifampicin survived while mice treated post-infection with the in vivo MIC equivalent dose of rifampicin followed by the in vivo MBC equivalent dose of rifampicin showed a $12.5 \%$ survival rate.

Therefore, preliminary data support that antimicrobial agents may be used for the treatment of an E. coli O157:H7 infection. One promising treatment modality, as evidenced by our in vivo data, may be to implement an expression inhibitory dose of an agent that would limit toxin production prior to using a bactericidal dose of an antimicrobial. Such a treatment modality may also be of use in treating other Shiga toxin producing organisms including emerging agents such as Escherichia coli O104:H4; however, potential implementation of such a treatment remains to be assessed.

Cimolai, N., Basalyga, S., Mah, D. G., Morrison, B. J., and Carter, J. E. (1994). A continuing assessment of risk factors for the development of Escherichia coli O157:H7-associated hemolytic uremic syndrome. Clin. Nephrol. 42, 85-89.

Devinney, R., Stein, M., Reinscheid, D., Abe, A., Ruschkowski, S., and Finlay, B. B. (1999). Enterohemorrhagic Escherichia coli O157:H7 produces Tir, which is translocated to the host cell membrane but is not tyrosine phosphorylated. Infect. Immun. 67, 2389-2398.

Diaz, S., Vidal, D., HerreraLeon, S., and Sanchez, S. (2011). Sorbitol-fermenting, $\beta$ glucuronidase-positive, Shiga toxin-negative Escherichia coli O157:H7 in free-ranging red deer in South-Central Spain. Foodborne Pathog. Dis. 8, 1313-1315.

Donohue-Rolfe, A., Kondova, I., Mukherjee, J., Chios, K., Hutto, D., and Tzipori, S. (1999). Antibodybased protection of gnotobiotic piglets infected with Escherichia coli O157:H7 against systemic complications associated with Shiga toxin 2. Infect. Immun. 67, 3645-3648.

Doyle, M. P., Beuchat, L. R., and Montville, T. J. (2001). Food Microbiology: Fundamentals and Frontiers. Washington, DC: ASM Press.

Etienne-Mesmin, L., Livrelli, V., Privat, M., Denis, S., Cardot, J. M., Alric,
M., et al. (2011). Effect of a new probiotic Saccharomyces cerevisiae strain on survival of Escherichia coli O157:H7 in a dynamic gastrointestinal model. Appl. Environ. Microbiol. 77, 1127-1131.

Friedman, M. S., Roels, T., Koehler, J. E., Feldman, L., Bibb, W. F., and Blake, P. (1999). Escherichia coli O157:H7 outbreak associated with an improperly chlorinated swimming pool. Clin. Infect. Dis. 29, 298-303.

Gagnon, M., Kheadr, E. E., Dabour, N., Richard, D., and Fliss, I. (2006). Effect of Bifidobacterium thermacidophilum probiotic feeding on enterohemorrhagic Escherichia coli O157:H7 infection in BALB/c mice. Int. J. Food Microbiol. 111, 26-33.

Gasser, C., Gautier, E., Steck, A., Siebenmann, R. E., and Oechslin, R. (1955). [Hemolytic-uremic syndrome: bilateral necrosis of the renal cortex in acute acquired hemolytic anemia]. Schweiz. Med. Wochenschr. 85, 905-909.

Gianantonio, C., Vitacco, M., Mendilaharzu, F., Rutty, A., and Mendilaharzu, J. (1964). The Hemolytic-Uremic Syndrome. J. Pediatr. 64, 478-491.

Griffin, P. M., Bell, B. P., Cieslak, P. R., Tuttle, J., Barrett, T. J., Doyle, M. P., et al. (1994). "Large outbreak of Escherichia coli O157:H7 infections in the Western United States: the big picture," in Recent Advances in 
Verocytotoxin-producing Escherichia coli Infections, eds M. A. Karmali and A. G. Goglio (Amsterdam: Elsevier Science, B.V), 7-12.

Griffin, P. M., Ostroff, S. M., Tauxe, R. V., Greene, K. D., Wells, J. G., Lewis, J. H., et al. (1988). Illnesses associated with Escherichia coli O157:H7 infections. A broad clinical spectrum. Ann. Intern. Med. 109, 705-712.

Griffin, P. M., and Tauxe, R. V. (1991). The epidemiology of infections caused by Escherichia coli O157:H7, other enterohemorrhagic E. coli, and the associated hemolytic uremic syndrome. Epidemiol. Rev. 13, 60-98.

Hilborn, E. D., Mermin, J. H., Mshar, P. A., Hadler, J. L., Voetsch, A., Wojtkunski, C., et al. (1999). A multistate outbreak of Escherichia coli O157:H7 infections associated with consumption of mesclun lettuce. Arch. Intern. Med. 159, 1758-1764.

Hofmann, S. L. (1993). Southwestern Internal Medicine Conference: Shiga-like toxins in hemolyticuremic syndrome and thrombotic thrombocytopenic purpura. Am. J. Med. Sci. 306, 398-406.

Ito, H., Terai, A., Kurazono, H., Takeda, Y., and Nishibuchi, M. (1990). Cloning and nucleotide sequencing of Vero toxin 2 variant genes from Escherichia coli O91:H21 isolated from a patient with the hemolytic uremic syndrome. Microb. Pathog. 8 , 47-60.

Jackson, M. P. (1990). Structurefunction analyses of Shiga toxin and the Shiga-like toxins. Microb. Pathog. 8, 235-242.

Kanbar, A., Rahal, E., and Matar, G. M. (2003). In vitro inhibition of the expression of Escherichia coli O157:H7 genes encoding the Shigalike toxins by antimicrobial agents: potential use in the treatment of human infection. J. Appl. Res. 3, 137-143.

Karmali, M. A., Petric, M., Lim, C., Fleming, P. C., and Steele, B. T. (1983). Escherichia coli cytotoxin, haemolytic-uraemic syndrome, and haemorrhagic colitis. Lancet 2, 1299-1300.

Kataoka, Y., Irie, Y., Sawada, T., and Nakazawa, M. (2010). A 3-year epidemiological surveillance of Escherichia coli O157:H7 in dogs and cats in Japan. J. Vet. Med. Sci. 72, 791-794.

Keene, W. E., McAnulty, J. M., Hoesly, F. C., Williams, L. P. Jr., Hedberg, K., Oxman, G. L., et al. (1994). A swimming-associated outbreak of hemorrhagic colitis caused by Escherichia coli $\mathrm{O} 157: \mathrm{H7}$ and
Shigella sonnei. N. Engl. J. Med. 331, 579-584.

Kim, Y., Oh, S., and Kim, S. H. (2009). Released exopolysaccharide (r-EPS) produced from probiotic bacteria reduce biofilm formation of enterohemorrhagic Escherichia coli O157:H7. Biochem. Biophys. Res. Commun. 379, 324-329.

Kimmitt, P. T., Harwood, C. R., and Barer, M. R. (2000). Toxin gene expression by shiga toxinproducing Escherichia coli: the role of antibiotics and the bacterial SOS response. Emerg. Infect. Dis. 6, 458-465.

Kresse, A. U., Beltrametti, F., Muller, A., Ebel, F., and Guzman, C. A. (2000). Characterization of SepL of enterohemorrhagic Escherichia coli. J. Bacteriol. 182, 6490-6498.

Kresse, A. U., Schulze, K., Deibel, C., Ebel, F., Rohde, M., Chakraborty, T., et al. (1998). Pas, a novel protein required for protein secretion and attaching and effacing activities of enterohemorrhagic Escherichia coli. J. Bacteriol. 180, 4370-4379.

Kudva, I. T., Blanch, K., and Hovde, C. J. (1998). Analysis of Escherichia coli O157:H7 survival in ovine or bovine manure and manure slurry. Appl. Environ. Microbiol. 64, 3166-3174.

Lacombe, A., Wu, V. C., Tyler, S., and Edwards, K. (2010). Antimicrobial action of the American cranberry constituents; phenolics, anthocyanins, and organic acids, against Escherichia coli O157:H7. Int. J. Food Microbiol. 139, 102-107.

Lee, K. M., Kim, W. S., Lim, J., Nam, S., Youn, M., Nam, S. W., et al. (2009). Antipathogenic properties of green tea polyphenol epigallocatechin gallate at concentrations below the MIC against enterohemorrhagic Escherichia coli O157:H7. J. Food Prot. 72, 325-331.

Lengacher, B., Kline, T. R., Harpster, L., Williams, M. L., and Lejeune, J. T. (2010). Low prevalence of Escherichia coli O157:H7 in horses in Ohio, USA. J. Food Prot. 73, 2089-2092.

Levine, M. M. (1987). Escherichia coli that cause diarrhea: enterotoxigenic, enteropathogenic, enteroinvasive, enterohemorrhagic, and enteroadherent. J. Infect. Dis. 155, 377-389.

Lopez, E. L., Contrini, M. M., Glatstein, E., Gonzalez Ayala, S., Santoro, R., Allende, D., et al. (2010). Safety and pharmacokinetics of urtoxazumab, a humanized monoclonal antibody, against Shiga-like toxin 2 in healthy adults and in pediatric patients infected with Shiga-like toxin-producing Escherichia coli.
Antimicrob. Agents Chemother. 54, 239-243.

Louie, M., De Azavedo, J. C., Handelsman, M. Y., Clark, C. G., Ally, B., Dytoc, M., et al. (1993). Expression and characterization of the eaeA gene product of Escherichia coli serotype O157:H7. Infect. Immun. 61, 4085-4092.

Low, A. S., Holden, N., Rosser, T., Roe, A. J., Constantinidou, C., Hobman, J. L., et al. (2006). Analysis of fimbrial gene clusters and their expression in enterohaemorrhagic Escherichia coli O157:H7. Environ. Microbiol. 8, 1033-1047.

March, S. B., and Ratnam, S. (1986). Sorbitol-MacConkey medium for detection of Escherichia coli O157:H7 associated with hemorrhagic colitis. J. Clin. Microbiol. 23, 869-872.

Matar, G. M., and Rahal, E. (2003). Inhibition of the transcription of the Escherichia coli O157:H7 genes coding for shiga-like toxins and intimin, and its potential use in the treatment of human infection with the bacterium. Ann. Trop. Med. Parasitol. 97, 281-287.

McDowell, D. A., and Sheridan, J. J. (2001). "Suvivial and growth of Vero cytotoxin-producing E. coli in the environment," in Verocytotoxigenic Escherichia coli, eds G. Duffy, P. Garvey, and D. McDowell (Trumbull, CT: Food and Nutrition Press Inc.), 279-304.

McLigeyo, S. O. (1999). Haemolytic uraemic syndrome: a review. East Afr. Med. J. 76, 148-153.

Mead, P. S., and Griffin, P. M. (1998). Escherichia coli O157:H7. Lancet 352, 1207-1212.

Mead, P. S., Slutsker, L., Dietz, V., McCaig, L. F., Bresee, J. S., Shapiro, C., et al. (1999). Food-related illness and death in the United States. Emerg. Infect. Dis. 5, 607-625.

Melton-Celsa, A. R., Kokai-Kun, J. F., and O'Brien, A. D. (2002). Activation of Shiga toxin type 2d (Stx2d) by elastase involves cleavage of the C-terminal two amino acids of the A2 peptide in the context of the appropriate B pentamer. Mol. Microbiol. 43, 207-215.

Melton-Celsa, A. R., and O'Brien, A. (1998). "Structure, biology, and relative toxicity of Shiga toxin family members for cells and animals," in Escherichia coli O157:H7 and Other Shiga toxin-producing E. coli Strains, eds J. B. Kaper and A. D. O'Brien (Washington, DC: American Society for Microbiology), 121-128. Mersha, G., Asrat, D., Zewde, B. M., and Kyule, M. (2010). Occurrence of Escherichia coli O157:H7 in faeces, skin and carcasses from sheep and goats in Ethiopia. Lett. Appl. Microbiol. 50, 71-76.

Meyers, K. E., and Kaplan, B. S. (2000). Many cell types are Shiga toxin targets. Kidney Int. 57, 2650-2651.

Michino, H., Araki, K., Minami, S., Takaya, S., Sakai, N., Miyazaki, M., et al. (1999). Massive outbreak of Escherichia coli O157:H7 infection in schoolchildren in Sakai City, Japan, associated with consumption of white radish sprouts. Am. J. Epidemiol. 150, 787-796.

Nataro, J. P., and Kaper, J. B. (1998). Diarrheagenic Escherichia coli. Clin. Microbiol. Rev. 11, 142-201.

Nauschuetz, W. (1998). Emerging foodborne pathogens: enterohemorrhagic Escherichia coli. Clin. Lab. Sci. 11, 298-304.

Nishikawa, K., Matsuoka, K., Kita, E., Okabe, N., Mizuguchi, M., Hino, K., et al. (2002). A therapeutic agent with oriented carbohydrates for treatment of infections by Shiga toxin-producing Escherichia coli O157:H7. Proc. Natl. Acad. Sci. U.S.A. 99, 7669-7674.

O'Brien, A. D., and Holmes, R. K. (1987). Shiga and Shiga-like toxins. Microbiol. Rev. 51, 206-220.

Ogawa, M., Shimizu, K., Nomoto, K., Takahashi, M., Watanuki, M., Tanaka, R., et al. (2001). Protective effect of Lactobacillus casei strain Shirota on Shiga toxin-producing Escherichia coli O157:H7 infection in infant rabbits. Infect. Immun. 69, 1101-1108.

Ogierman, M. A., Paton, A. W., and Paton, J. C. (2000). Up-regulation of both intimin and eae-independent adherence of shiga toxigenic Escherichia coli $\mathrm{O} 157$ by ler and phenotypic impact of a naturally occurring ler mutation. Infect. Immun. 68, 5344-5353.

Olsen, S. J., Miller, G., Breuer, T., Kennedy, M., Higgins, C., Walford, J., et al. (2002). A waterborne outbreak of Escherichia coli O157:H7 infections and hemolytic uremic syndrome: implications for rural water systems. Emerg. Infect. Dis. 8, 370-375.

Orth, D., Ehrlenbach, S., Brockmeyer, J., Khan, A. B., Huber, G., Karch, H., et al. (2010). EspP, a serine protease of enterohemorrhagic Escherichia coli, impairs complement activation by cleaving complement factors C3/C3b and C5. Infect. Immun. 78, 4294-4301.

Oussalah, M., Caillet, S., and Lacroix, M. (2006). Mechanism of action of Spanish oregano, Chinese cinnamon, and savory essential oils 
against cell membranes and walls of Escherichia coli O157:H7 and Listeria monocytogenes. J. Food Prot. 69, 1046-1055.

Pai, C. H., Ahmed, N., Lior, H., Johnson, W. M., Sims, H. V., and Woods, D. E. (1988). Epidemiology of sporadic diarrhea due to verocytotoxin-producing Escherichia coli: a two-year prospective study. J. Infect. Dis. 157, 1054-1057.

Panaro, L., Cooke, D., and Borczyk, A. (1990). Outbreak of Escherichia coli O157:H7 in a nursing home Ontario. Can. Dis. Wkly. Rep. 16, 90-92.

Paunio, M., Pebody, R., Keskimaki, M., Kokki, M., Ruutu, P., Oinonen, S., et al. (1999). Swimmingassociated outbreak of Escherichia coli O157:H7. Epidemiol. Infect. 122, 1-5.

Pruimboom-Brees, I. M., Morgan, T. W., Ackermann, M. R., Nystrom, E. D., Samuel, J. E., Cornick, N. A., et al. (2000). Cattle lack vascular receptors for Escherichia coli O157:H7 Shiga toxins. Proc. Natl. Acad. Sci. U.S.A. 97, 10325-10329.

Qadri, S. M., and Kayali, S. (1998). Enterohemorrhagic Escherichia coli. A dangerous food-borne pathogen. Postgrad. Med. 103, 179-180.

Raghubeer, E. V., and Matches, J. R. (1990). Temperature range for growth of Escherichia coli serotype O157:H7 and selected coliforms in E. coli medium. J. Clin. Microbiol. 28, 803-805.

Rahal, E. A., Kazzi, N., Kanbar, A., Abdelnoor, A. M., and Matar, G. M. (2011a). Role of rifampicin in limiting Escherichia coli O157:H7 Shigalike toxin expression and enhancement of survival of infected BALB/C mice. Int. J. Antimicrob. Agents 37, 135-139.

Rahal, E. A., Kazzi, N., Sabra, A., Abdelnoor, A. M., and Matar, G. M. (2011b). Decrease in Shiga toxin expression using a minimal inhibitory concentration of rifampicin followed by bactericidal gentamicin treatment enhances survival of Escherichia coli O157:H7infected BALB/c mice. Ann. Clin. Microbiol. Antimicrob. 10, 34.

Rangel, J. M., Sparling, P. H., Crowe, C., Griffin, P. M., and Swerdlow, D. L. (2005). Epidemiology of Escherichia coli O157:H7 outbreaks, United States, 1982-2002. Emerg. Infect. Dis. 11, 603-609.

Reida, P., Wolff, M., Pohls, H. W., Kuhlmann, W., Lehmacher, A., Aleksic, S., et al. (1994). An outbreak due to enterohaemorrhagic
Escherichia coli O157:H7 in a children day care centre characterized by person-to-person transmission and environmental contamination. Zentralbl. Bakteriol. 281, 534-543.

Riley, L. W., Remis, R. S., Helgerson, S. D., McGee, H. B., Wells, J. G., Davis, B. R., et al. (1983). Hemorrhagic colitis associated with a rare Escherichia coli serotype. $N$. Engl. J. Med. 308, 681-685.

Safdar, N., Said, A., Gangnon, R. E., and Maki, D. G. (2002). Risk of hemolytic uremic syndrome after antibiotic treatment of Escherichia coli O157:H7 enteritis: a metaanalysis. JAMA 288, 996-1001.

Sandvig, K., and Van Deurs, B. (1996). Endocytosis, intracellular transport, and cytotoxic action of Shiga toxin and ricin. Physiol. Rev. 76, 949-966.

Sato, T., Shimizu, T., Watarai, M., Kobayashi, M., Kano, S., Hamabata, T., et al. (2003). Genome analysis of a novel Shiga toxin 1 (Stx1)converting phage which is closely related to Stx2-converting phages but not to other Stx1-converting phages. J. Bacteriol. 185, 3966-3971.

Schmidt, H., Kernbach, C., and Karch, H. (1996). Analysis of the EHEC hly operon and its location in the physical map of the large plasmid of enterohaemorrhagic Escherichia coli O157:H7. Microbiology 142(Pt 4), 907-914

Schmidt, H., Scheef, J., Morabito, S., Caprioli, A., Wieler, L. H., and Karch, H. (2000). A new Shiga toxin 2 variant (Stx2f) from Escherichia coli isolated from pigeons. Appl. Environ. Microbiol. 66, 1205-1208.

Shimizu, T., Ohta, Y., and Noda, M. (2009). Shiga toxin 2 is specifically released from bacterial cells by two different mechanisms. Infect. Immun. 77, 2813-2823.

Shu, Q., and Gill, H. S. (2001). A dietary probiotic (Bifidobacterium lactis HN019) reduces the severity of Escherichia coli O157:H7 infection in mice. Med. Microbiol. Immunol. $189,147-152$.

Shu, Q., and Gill, H. S. (2002). Immune protection mediated by the probiotic Lactobacillus rhamnosus HN001 (DR20) against Escherichia coli O157:H7 infection in mice. FEMS Immunol. Med. Microbiol. 34, 59-64.

Siegler, R. L. (1995). The hemolytic uremic syndrome. Pediatr. Clin. North Am. 42, 1505-1529.

Slutsker, L., Ries, A. A., Greene, K. D., Wells, J. G., Hutwagner, L., and Griffin, P. M. (1997). Escherichia coli O157:H7 diarrhea in the United States: clinical and epidemiologic features. Ann. Intern. Med. 126, 505-513.

Smith, K. E., Wilker, P. R., Reiter, P. L., Hedican, E. B., Bender, J. B., and Hedberg, C. W. (2012). Antibiotic treatment of Escherichia coli O157 infection and the risk of hemolytic uremic syndrome, Minnesota. Pediatr. Infect. Dis. J. 31, 37-41.

Strockbine, N. A., Marques, L. R., Newland, J. W., Smith, H. W., Holmes, R. K., and O'Brien, A. D. (1986). Two toxin-converting phages from Escherichia coli O157:H7 strain 933 encode antigenically distinct toxins with similar biologic activities. Infect. Immun. 53, 135-140.

Swerdlow, D. L., Woodruff, B. A., Brady, R. C., Griffin, P. M., Tippen, S., Donnell, H. D. Jr., et al. (1992). A waterborne outbreak in Missouri of Escherichia coli O157:H7 associated with bloody diarrhea and death. Ann. Intern. Med. 117, 812-819.

Tahamtan, Y., Kargar, M., Namdar, N., Rahimian, A., Hayati, M., and Namavari, M. M. (2011). Probiotic inhibits the cytopathic effect induced by Escherichia coli O157:H7 in Vero cell line model. Lett. Appl. Microbiol. 52, 527-531.

Takahashi, M., Taguchi, H., Yamaguchi, H., Osaki, T., Komatsu, A., and Kamiya, S. (2004). The effect of probiotic treatment with Clostridium butyricum on enterohemorrhagic Escherichia coli O157:H7 infection in mice. FEMS Immunol. Med. Microbiol. 41, 219-226.

Tesh, V. L., and O'Brien, A. D. (1992). Adherence and colonization mechanisms of enteropathogenic and enterohemorrhagic Escherichia coli. Microb. Pathog. 12, 245-254.

Urdahl, A. M., Beutin, L., Skjerve, E., Zimmermann, S., and Wasteson, Y. (2003). Animal host associated differences in Shiga toxin-producing Escherichia coli isolated from sheep and cattle on the same farm. J. Appl. Microbiol. 95, 92-101.

Vallance, B. A., and Finlay, B. B. (2000). Exploitation of host cells by enteropathogenic Escherichia coli. Proc. Natl. Acad. Sci. U.S.A. 97, 8799-8806.

Van Gorp, E. C., Suharti, C., Ten Cate, H., Dolmans, W. M., Van Der Meer, J. W., Ten Cate, J. W., et al. (1999). Review: infectious diseases and coagulation disorders. J. Infect. Dis. 180, 176-186.

Wang, G., and Doyle, M. P. (1998). Survival of enterohemorrhagic Escherichia coli O157:H7 in water. J. Food Prot. 61, 662-667.
Wong, C. S., Jelacic, S., Habeeb, R. L., Watkins, S. L., and Tarr, P. I. (2000). The risk of the hemolyticuremic syndrome after antibiotic treatment of Escherichia coli O157:H7 infections. N. Engl. J. Med. 342, 1930-1936.

Xicohtencatl-Cortes, J., MonteiroNeto, V., Ledesma, M. A., Jordan, D. M., Francetic, O., Kaper, J. B., et al. (2007). Intestinal adherence associated with type IV pili of enterohemorrhagic Escherichia coli O157:H7. J. Clin. Invest. 117, 3519-3529.

Yoh, M., Frimpong, E. K., and Honda, T. (1997). Effect of antimicrobial agents, especially fosfomycin, on the production and release of Vero toxin by enterohaemorrhagic Escherichia coli O157:H7. FEMS Immunol. Med. Microbiol. 19, 57-64.

Zhang, Q., Donohue-Rolfe, A., KrautzPeterson, G., Sevo, M., Parry, N., Abeijon, C., et al. (2009). Gnotobiotic piglet infection model for evaluating the safe use of antibiotics against Escherichia coli O157:H7 infection. J. Infect. Dis. 199, 486-493.

Zheng, J., Cui, S., Teel, L. D., Zhao, S., Singh, R., O’Brien, A. D., et al. (2008). Identification and characterization of Shiga toxin type 2 variants in Escherichia coli isolates from animals, food, and humans. Appl. Environ. Microbiol. 74, 5645-5652.

Conflict of Interest Statement: The authors declare that the research was conducted in the absence of any commercial or financial relationships that could be construed as a potential conflict of interest.

Received: 17 May 2012; paper pending published: 18 June 2012; accepted: 19 October 2012; published online: 15 November 2012.

Citation: Rahal EA, Kazzi N, Nassar FJ and Matar GM (2012) Escherichia coli O157:H7-Clinical aspects and novel treatment approaches. Front. Cell. Inf. Microbio. 2:138. doi: 10.3389/fcimb. 2012.00138

Copyright (c) 2012 Rahal, Kazzi, Nassar and Matar. This is an open-access article distributed under the terms of the Creative Commons Attribution License, which permits use, distribution and reproduction in other forums, provided the original authors and source are credited and subject to any copyright notices concerning any third-party graphics etc. 